\title{
Gait Analysis of Foot Compensation After Arthrodesis of the First Metatarsophalangeal Joint
}

Citation for published version (APA):

Stevens, J., Meijer, K., Bijnens, W., Fuchs, M. C. H. W., van Rhijn, L. W., Hermus, J. P. S., van Hoeve, S., Poeze, M., \& Witlox, A. M. (2017). Gait Analysis of Foot Compensation After Arthrodesis of the First Metatarsophalangeal Joint. Foot \& Ankle International, 38(2), 181-191.

https://doi.org/10.1177/1071100716674310

Document status and date:

Published: 01/02/2017

DOI:

10.1177/1071100716674310

Document Version:

Publisher's PDF, also known as Version of record

Document license:

Taverne

Please check the document version of this publication:

- A submitted manuscript is the version of the article upon submission and before peer-review. There can be important differences between the submitted version and the official published version of record.

People interested in the research are advised to contact the author for the final version of the publication, or visit the DOI to the publisher's website.

- The final author version and the galley proof are versions of the publication after peer review.

- The final published version features the final layout of the paper including the volume, issue and page numbers.

Link to publication

\footnotetext{
General rights rights.

- You may freely distribute the URL identifying the publication in the public portal. please follow below link for the End User Agreement:

www.umlib.nl/taverne-license

Take down policy

If you believe that this document breaches copyright please contact us at:

repository@maastrichtuniversity.nl

providing details and we will investigate your claim.
}

Copyright and moral rights for the publications made accessible in the public portal are retained by the authors and/or other copyright owners and it is a condition of accessing publications that users recognise and abide by the legal requirements associated with these

- Users may download and print one copy of any publication from the public portal for the purpose of private study or research.

- You may not further distribute the material or use it for any profit-making activity or commercial gain

If the publication is distributed under the terms of Article $25 \mathrm{fa}$ of the Dutch Copyright Act, indicated by the "Taverne" license above, 


\title{
Gait Analysis of Foot Compensation After Arthrodesis of the First Metatarsophalangeal Joint
}

2017, Vol. 38(2) $|8|-19 \mid$

(C) The Author(s) 2016

Reprints and permissions:

sagepub.com/journalsPermissions.nav DOI: $10.1177 / 1071100716674310$

journals.sagepub.com/home/fai

\author{
Jasper Stevens, MD', Kenneth Meijer, PhD², Wouter Bijnens, BScEng ${ }^{2}$, \\ Mathijs C.H.W. Fuchs, MD', Lodewijk W. van Rhijn, Prof, MD', \\ Joris P.S. Hermus, MD', Sander van Hoeve, MD³, Martijn Poeze, MD, PhD³, \\ and Adhiambo M. Witlox, MD, PhD'
}

\begin{abstract}
Background: Arthrodesis of the first metatarsophalangeal (MTPI) joint is an intervention often used in patients with severe MTPI joint osteoarthritis and relieves pain in approximately $80 \%$ of these patients. The kinematic effects and compensatory mechanism of the foot for restoring a more normal gait pattern after this intervention are unknown. The aim of this study was to clarify this compensatory mechanism, in which it was hypothesized that the hindfoot and forefoot would be responsible for compensation after an arthrodesis of the MTPI joint.

Methods: Gait properties were evaluated in 10 feet of 8 patients with MTPI arthrodesis and were compared with 21 feet of 12 healthy subjects. Plantar pressures and intersegmental range of motion were measured during gait by using the multisegment Oxford Foot Model. Pre- and postoperative X-rays of the foot and ankle were also evaluated.

Results: The MTPI arthrodesis caused decreased eversion of the hindfoot during midstance, followed by an increased internal rotation of the hindfoot during terminal stance, and ultimately more supination and less adduction of the forefoot during preswing. In addition, MTPI arthrodesis resulted in a lower pressure time integral beneath the hallux and higher peak pressures beneath the lesser metatarsals. A mean dorsiflexion fusion angle of $30 \pm 5.4$ degrees was observed in postoperative radiographs.

Conclusion: This study demonstrated that the hindfoot and forefoot compensated for the loss of motion of the MTPI joint after arthrodesis in order to restore a more normal gait pattern. This resulted in a gait in which the rigid hallux was less loaded while the lesser metatarsals endured higher peak pressures. Further studies are needed to investigate whether this observed transfer of load or a preexistent decreased compensatory mechanism of the foot can possibly explain the disappointing results in the minority of the patients who experience persistent complaints after a MTPI arthrodesis.

Level of Evidence: Level III, comparative series.
\end{abstract}

Keywords: MTPI arthrodesis, hallux, gait analysis, Oxford Foot Model, multisegment foot model, plantar pressure, compensatory mechanism

\section{Introduction}

Osteoarthritis (OA) of the first metatarsophalangeal (MTP1) joint is a common disorder of the musculoskeletal system in elderly, which progresses with age. ${ }^{40}$ The exact etiology of MTP1 joint OA is unknown, although trauma, overuse, operations, deformations, and the length of the first metatarsal seem to be involved. ${ }^{6,34}$ Patients usually present with pain, stiffness, and swelling of the MTP1 joint. Erythema and a limited range of motion of this joint are observed during physical examination, while conventional radiographs show degenerative changes of the MTP1 joint. ${ }^{7,14}$

First metatarsophalangeal joint OA severely affects quality of life since patients experience chronic pain and more difficulties while performing physical tasks and daily activities. $^{4}$ An arthrodesis of the MTP1 joint is the preferred

\footnotetext{
'Department of Orthopaedics, Maastricht University Medical Centre, The Netherlands

${ }^{2}$ Department of Human Movement Sciences, Maastricht University, The Netherlands

${ }^{3}$ Department of Surgery, Division of Trauma surgery, Maastricht

University Medical Centre, The Netherlands

Corresponding Author:

Jasper Stevens, MD, Department of Orthopaedics, Maastricht University Medical Centre, P Debyelaan 25, PO Box 5800, 6202AZ Maastricht, The Netherlands.

Email: jasper.stevens@student.maastrichtuniversity.nl
} 
intervention to relieve pain when the articular cartilage is extensively damaged and patients have been refractory to conservative treatment. Approximately $80 \%$ of the patients were satisfied after this intervention, in which an arthrodesis alleviated pain complaints and increased function. . $^{17,19,21,24,29,30}$ The reason for dissatisfaction in the remaining $20 \%$ of the patients is unknown. It is reasonable to assume that adjacent joints in the foot will compensate for the lack of motion in the MTP1 joint after an arthrodesis in order to restore foot function. An impaired ability of these adjacent joints to compensate for the motionless MTP1 joint can possibly explain the disappointing results of some MTP1 arthrodeses. However, it is not known if and how the foot compensates for restoring the gait pattern toward a normal gait pattern after this intervention.

Motion capture analysis, in which the human body is divided in several segments, allows for measurements and analysis of motion between these segments during gait. This method provides an opportunity to clarify which joints are responsible for restoring the gait pattern after a MTP1 arthrodesis. To our knowledge, only 3 studies $^{5,16,22}$ used motion capture analysis to assess gait properties after a MTP1 arthrodesis and showed a decrease in step length and step width, although no differences in foot kinematics were detected after this intervention. However, these studies were particularly limited by the gait models used, which presented the foot as a single segment instead of multiple segments. This would be more representative since the foot consists of 26 bones. As a result, the compensatory mechanism after a MTP1 arthrodesis remains unknown.

The goal of this study was to elucidate where the foot compensates for the loss of motion after an MTP1 arthrodesis in order to restore the gait pattern toward a normal gait pattern. Currently, there is no foot model available describing motion between all individual foot joints. Therefore, the 4-segment Oxford Foot Model (OFM) was used to evaluate foot kinematics. This foot model divided the foot and ankle in a tibial, hindfoot, forefoot, and hallux segment. Plantar peak pressures, which provided information on the maximal pressure in a plantar area at one moment during stance, and pressure-time integrals, which provided information of total loading of a plantar area during the entire stance phase, were measured to investigate the effect of a MTP1 arthrodesis on foot loading.

We hypothesized that the hindfoot and forefoot would compensate for the absence of motion in the MTP1 joint after an arthrodesis by showing less eversion and more supination, respectively, as it would be expected that the rigid hallux would be avoided during roll-off. As a result, decreased loading of the hallux and increased loading of the lesser metatarsals would be expected during the stance phase of gait.

\section{Materials and Methods}

\section{Study Population}

This cross-sectional study was conducted at the Human Movement Laboratory of our institution. Potential candidates were identified in the patient files of the department of orthopaedics of our institution. Patients who underwent MTP1 arthrodesis for symptomatic OA of the MTP1 joint in the past 5 years, with a clinical and radiographic consolidation of the arthrodesis, and a minimum follow-up of 1 year were eligible for participation. Patients with an arthrodesis of another joint in the same foot, who required assistance when walking, or were unable to walk more than 100 meters barefoot were excluded. In addition, patients with a total knee prosthesis, a total hip prosthesis, diabetes mellitus, inflammatory joint disease, or neurological disease influencing gait were not eligible for participation in this study. Patients were compared to healthy subjects with no medical history resulting in an abnormal gait pattern (ie, fractures or deformities of the lower extremities, neurological brain, or spinal cord injury). Approval for this study was obtained from the local ethics committee, and all patients provided written informed consent.

Overall, 8 patients were included, of which 6 patients underwent a unilateral MTP1 arthrodesis and 2 patients a bilateral MTP1 arthrodesis, resulting in a total of 10 feet with MTP1 arthrodesis. Twelve healthy subjects were included ( 9 of whom were measured bilaterally), resulting in a total of 21 control feet.

\section{Operative Technique}

All patients were operated between December 2010 and May 2014 by 2 orthopaedic surgeons. Briefly, a longitudinal dorsomedial incision was used. Socked and ball reaming of the metatarsal head and base of the proximal phalanx was applied. Fixation was established with the "HALLUFIX Integra plate" (Integra Life Sciences, Plainsboro, NJ, USA). During the postoperative period, patients were immobilized with a non-weight bearing cast for 4 weeks, followed by a weight-bearing cast for the subsequent 4 weeks. No complications of the primary surgical intervention (ie, infection or revision surgery) were reported.

\section{Radiographic evaluation}

Two independent observers, who were blinded to the gait analysis and patient outcome, evaluated preoperative and postoperative radiographs. The following parameters were evaluated on radiographs: intermetatarsal angle (IMA), hallux valgus angle (HVA), and hallux interphalangeal angle. ${ }^{35}$ The dorsiflexion fusion angle (DFA) was measured as described by Coughlin. ${ }^{12}$ Mean angles of both measurements 
were calculated. Differences between observers greater than 5 degrees were resolved by consensus. Radiographic consolidation of the MTP1 arthrodesis was confirmed in all patients.

\section{Motion analysis}

Motion capture was conducted using a Vicon system (Vicon Motion Systems, Oxford, UK), consisting of 16 infrared cameras ( $8 \mathrm{~T} 10,6 \mathrm{MX} 3$, and $2 \mathrm{~T} 20$ running at $200 \mathrm{~Hz})$. One trained researcher placed all 42 markers (Supplement 1 available in the online journal) according to the OFM protocol after careful identification of the bony landmarks. The OFM is a 4-segment model of the foot and divides the foot and ankle in a tibial (tibia and fibula), hindfoot (calcaneus and talus), forefoot (5 metatarsals), and hallux segment and has been validated to measure intersegmental motion in the sagittal, coronal, and transverse planes. ${ }^{9,39,41}$ A 10-meter runway was equipped with a forceplate (AMTI OR6 Series, Advanced Mechanical Technology Inc, Watertown, NY, USA) running at a frequency of $1000 \mathrm{~Hz}$ and was synchronized with the Vicon Nexus 1.8.5 software. Dynamic plantar pressures were measured using a pressure plate (High Speed Advanced Footscan System, RSscan International, Paal, Belgium), which had a sampling frequency of $253 \mathrm{~Hz}$. The pressure plate was mounted on top of the forceplate and was also synchronized with Vicon Nexus 1.8.5.

The following patient characteristics were measured for running the OFM: height, weight, knee and ankle width (distance between the lateral and medial condyle of the knee and the distance between the lateral and medial malleolus of the ankle, respectively), and leg length (distance between the anterior iliac spine and the medial malleolus). One trained researcher performed all measurements. Markers were calibrated, and subject-specific axes were calculated during 1 static trial, with the patients standing in an anatomically neutral position. After this static trial, 3 markers were removed according to the OFM protocol, and patients were asked to walk at a comfortable speed with their eyes focused on the wall in front of them. After the practice trials, at least 15 proper recordings with the subject cleanly striking the pressure plate were obtained while walking barefoot.

\section{Data processing}

Markers were tracked and labeled using Vicon Nexus 1.8.5. Intersegmental range of motion and spatio-temporal parameters of interest were calculated with MATLAB software (version R2012A, The MathWorks Inc, Natick, MA, USA). All trials with a gait velocity ranging between 2 standard deviations of the subjects' own average speed were used for further analysis. The pelvic segment center of mass, which was estimated based on the pelvic markers, was used to define gait velocity. Stance time was defined as the time between heel strike and toe off of the foot of interest. Step length was calculated as the distance between both heel markers in the direction of gait, while step width was the distance between these markers in the plane perpendicular to the direction of gait. Intersegmental range of motion (ROM) was calculated for the hindfoot-tibia and forefoothindfoot segment in the frontal plane (ie, inversion/eversion and pronation/supination, respectively), sagittal plane (ie, dorsiflexion/plantarflexion), and transverse plane (ie, external/internal rotation and abduction/adduction, respectively) and for the hallux-forefoot segment in the sagittal plane (ie, dorsiflexion/plantarflexion). The ROM was calculated for the 4 phases of stance as defined by Perry ${ }^{32}$ after time normalization of the gait cycle. These phases were the loading response ( $0 \%-17 \%$ of stance phase), midstance (18\%-50\%), terminal stance $(51 \%-83 \%)$, and preswing $(84 \%-100 \%)$. The ROM was defined as the difference between the minimum and maximum joint angle during each phase. Initial contact was identified as the onset of a vertical ground reaction force exceeding 20 Newtons $(\mathrm{N})$, and toe off was identified as the first moment after initial contact with the vertical ground reaction force below $20 \mathrm{~N}$. The ROM was averaged for at least 6 trials per subject, which has proven to be a sufficient number of trials to achieve high intraclass correlation coefficients for the OFM. ${ }^{39}$

Since it is known that bilateral disease can influence compensatory mechanisms, motion patterns of the segments of interest and the pelvis, hip, and knee of bilateral and unilateral treated patients were compared to assess this influence. In addition, left and right feet of healthy subjects were compared to assess if analysis of both feet influences outcome.

For analysis of dynamic plantar pressure, the foot was automatically divided in 10 anatomical areas (ie, the hallux $\left[\mathrm{Toe}_{1}\right]$, lesser toes $\left[\mathrm{Toe}_{2-5}\right]$, metatarsal heads [Meta - -Meta ${ }_{5}$, midfoot, medial heel, and lateral heel) by the Footscan 7.0 Gait 2nd Generation software. Trials with inconsistencies in the automatic masking procedure were manually adjusted. An ASCII output was generated in which peak pressures (PP), force-time integrals, and contact areas were obtained. Peak pressure was defined as the highest magnitude measured by any sensor in an area and reflects the highest value in a peak pressure-time curve of a particular area. The forcetime integral and contact area were used for calculating the pressure-time integral (PTI) as described by Melai et al. ${ }^{31}$ This alternative calculation of the PTI described the cumulative effect of pressure on a plantar area over time (ie, area under the peak pressure-time curve) instead of summing the PP per timeframe for an entire trial. It thereby provided a more representative value of the total load exposure of a plantar area during stance. Both PP and PTI were calculated for the 10 described areas. 
Table I. Patient Characteristics. ${ }^{a}$

\begin{tabular}{|c|c|c|c|}
\hline & MTPI Arthrodesis & Healthy Control & $P$ Value \\
\hline No. of subjects (No. of feet) & $8(10)$ & $12(2 \mid)$ & - \\
\hline $\mathrm{Age}^{\mathrm{b}}(\mathrm{y})$ & $59.4 \pm 8.3(50-69)$ & $43.1 \pm 18.2(20-65)$ & .003 \\
\hline No. (\% of subjects) male & $2(25)$ & $9(75)$ & - \\
\hline No. (\% of feet) right side & $5(50.0)$ & II (52.4) & - \\
\hline Weight (kg) & $78.1 \pm 21.0(55.0-108.3)$ & $75.3 \pm 9.7(62.0-91.0)$ & .731 \\
\hline Height $^{b}(\mathrm{~cm})$ & $168.2 \pm 9.45(157.0-184.0)$ & $|79.6 \pm 5.0|(\mid 68.5-185.0)$ & .002 \\
\hline Body mass index ${ }^{b}\left(\mathrm{~kg} / \mathrm{m}^{2}\right)$ & $27.1 \pm 4.4(22.3-33.6)$ & $23.3 \pm 2.5(19.4-26.9)$ & .050 \\
\hline Leg length (cm) & $89.80 \pm 5.55(80.0-99.0)$ & $93.43 \pm 23.3(78.0-97.0)$ & .068 \\
\hline Knee width $(\mathrm{cm})$ & $10.48 \pm 1.05(9.5-12.2)$ & $10.41 \pm 0.66(9.3-12.0)$ & .819 \\
\hline Ankle width $(\mathrm{cm})$ & $6.94 \pm 0.49(6.4-7.7)$ & $6.92 \pm 0.47(6.1-7.7)$ & .721 \\
\hline
\end{tabular}

a Mean values and standard deviations with the range in parentheses are presented. MTPI, first metatarsophalangeal joint.

${ }^{b}$ Significant difference between MTPI arthrodesis and healthy control $P<.05$.

\section{Statistical analysis}

Statistical analyses were performed with SPSS software (version 23; IBM, Armonk, NY, USA). The Shapiro-Wilk test was performed to assess whether gait parameters were normally distributed. Log linear transformations were used for not normally distributed data. The unpaired Student $t$ test was used to detect differences in patient characteristics, spatio-temporal parameters, intersegmental ROM, and plantar pressure data between patients and healthy subjects. Differences in radiographic angles between pre- and postoperative radiographs and differences in intersegmental ROM in both feet of bilateral evaluated healthy controls were tested with the paired $t$ test. A $P$ value less than .05 was considered to be statistically significant for patient characteristics, spatio-temporal parameters, and plantar pressure data. To adjust for multiple tests over the 4 phases of stance, a Bonferroni correction was applied to achieve an overall error rate of 5\%. Therefore, a $P$ value less than .0125 was considered to be statistically significant for differences in intersegmental ROM.

\section{Results}

\section{Patient characteristics}

Baseline patient characteristics are presented in Table 1 and depict differences between both groups. Healthy subjects were significantly younger $(P=.003)$, had a greater height $(P$ $=.002)$ and lower body mass index $(P=.05)$, and contained more male participants compared to the MTP1 arthrodesis group. Radiographic angles are presented in Table 2, showing a significant decrease in IMA and HVA $(P=.02$ and $P=$ .03 , respectively) after MTP1 arthrodesis. The mean postoperative DFA was $30.0 \pm 5.4$ degrees (range, 21-35 degrees).

\section{Gait analysis}

Gait analysis took place at a median follow-up of 27 months (range, 18-60 months) postoperatively. With the numbers
Table 2. Radiographic Evaluation of Preoperative and Postoperative Radiographs.

\begin{tabular}{lccc}
\hline Radiographic Evaluation & Preoperative & Postoperative & $P$ Value \\
\hline IMA (degrees) $^{\mathrm{a}}$ & $10.8 \pm 3.4$ & $8.7 \pm 2.4$ & .02 \\
HVA (degrees) & $16.4 \pm 7.8$ & $10.7 \pm 5.5$ & .03 \\
IPA (degrees) & $12.1 \pm 4.7$ & $12.8 \pm 2.8$ & .59 \\
DFA (degrees) & - & $30.0 \pm 5.4$ & - \\
\hline
\end{tabular}

Abbreviations: DFA, dorsiflexion fusion angle; HVA, hallux valgus angle; IMA, intermetatarsal angle; IPA, inter phalangeal angle.

${ }^{a}$ Significant difference between first metatarsophalangeal joint arthrodesis and healthy control $P<.05$.

Table 3. Spatio-Temporal Parameters of Gait for the MTPI Arthrodesis and Healthy Control Group. ${ }^{a}$

MTPI Arthrodesis Healthy Control $P$ Value

\begin{tabular}{llll}
\hline Gait velocity $(\mathrm{m} / \mathrm{s})$ & $1.18 \pm 0.25$ & $1.17 \pm 0.19$ & .867 \\
Stance time $(\mathrm{s})$ & $0.70 \pm 0.11$ & $0.70 \pm 0.08$ & .946 \\
Step length $(\mathrm{m})$ & $0.61 \pm 0.08$ & $0.57 \pm 0.05$ & .168 \\
Step width $(\mathrm{m})^{\mathrm{a}}$ & $0.08 \pm 0.03$ & $0.13 \pm 0.04$ & .001
\end{tabular}

${ }^{a}$ Data are presented as mean values and standard deviation. MTPI, first metatarsophalangeal joint.

${ }^{\mathrm{a}}$ Significant difference between MTPI arthrodesis and healthy control $P<.05$.

available, no significant differences in gait velocity, stance time, and step length were detected between both groups, as is shown in Table 3. Step width was significantly smaller in the MTP1 arthrodesis group compared to the healthy controls $(P=.001)$.

Kinematic results are presented in Figure 1 and Figure 2. The MTP1 arthrodesis group showed a significantly increased ROM in the terminal stance phase in the transverse plane in the hindfoot-tibia segment $(P=.002$, Figure $1 \mathrm{~A})$, which was the result of a more internally rotated hindfoot (Figure 2A). A significantly decreased ROM was observed after a MTP1 arthrodesis in the frontal plane during midstance in this 


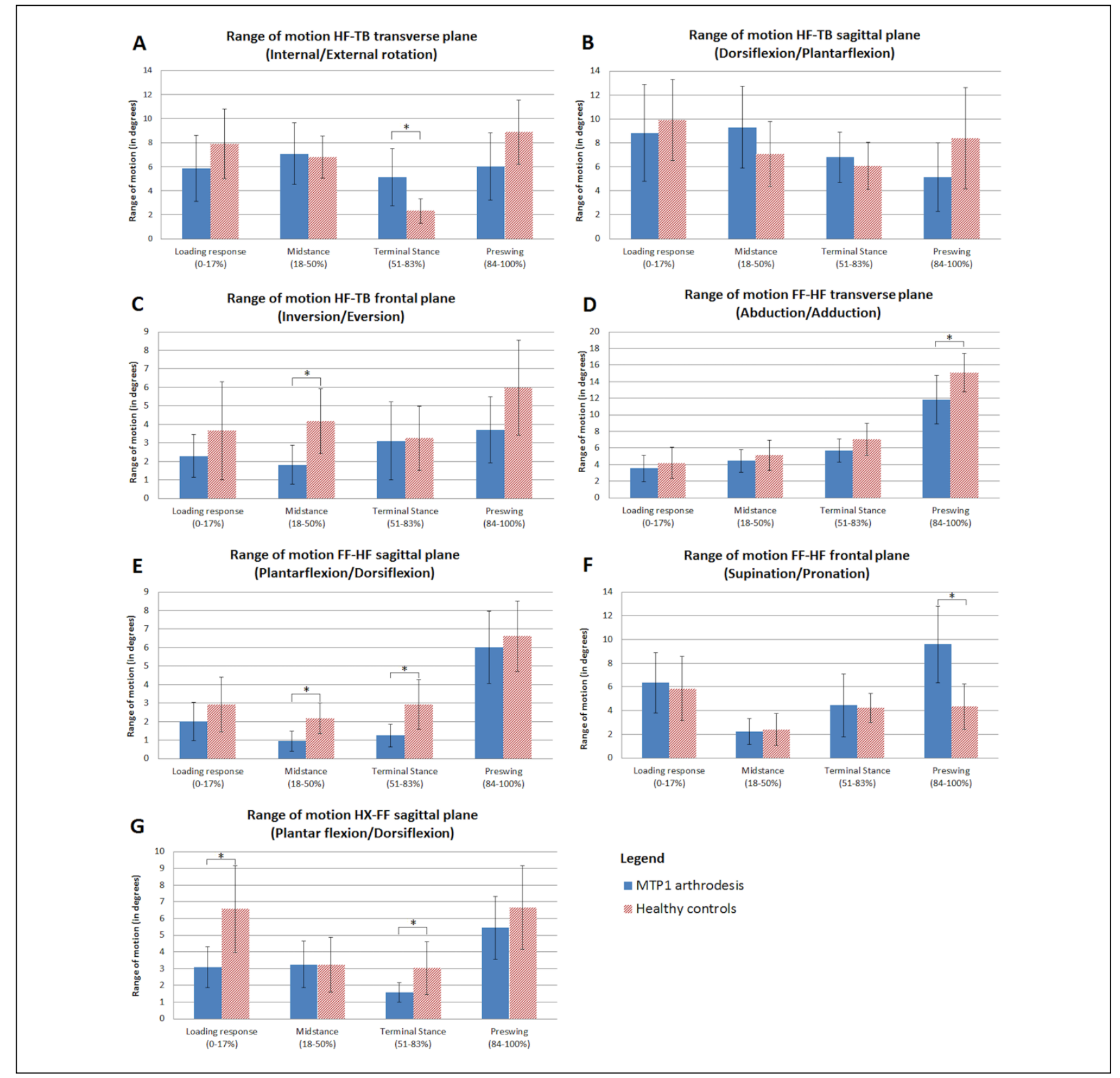

Figure I. Range of motion in the (A-C) hindfoot-tibia segment, (D-F) forefoot-hindfoot segment, and (G) hallux-forefoot segment in the transverse, sagittal, and frontal planes during stance for the first metatarsophalangeal joint arthrodesis group and healthy controls. *Indicates a significant difference in range of motion $(P<.0125)$.

segment $(P=.001$, Figure 1C), due to diminished eversion of the hindfoot (Figure 2C). No significant differences could be detected in sagittal plane motion in the hindfoot-tibia segment (Figure 1B and Figure 2B).

Transverse plane motion showed a significantly reduced ROM after a MTP1 arthrodesis in the forefoot-hindfoot segment during preswing $(P=.003$, Figure 1D), due to diminished adduction of the forefoot in this phase (Figure 2D). In addition, significantly less plantarflexion was observed during midstance $(P<.001$, Figure $2 \mathrm{E})$ and terminal stance $(P=.001$, Figure $2 \mathrm{E})$ in this segment, which resulted in a significantly reduced ROM in the sagittal plane in the MTP1 arthrodesis group (Figure 1E). A significant increase in ROM after a MTP1 arthrodesis, as a result of increased supination of the forefoot $(P<.001$, Figure $1 \mathrm{~F}$ and Figure $2 \mathrm{~F}$ ), was detected in the frontal plane during preswing in the forefoot-hindfoot segment.

Decreased ROM of the hallux was observed in the loading response $(P<.001$, Figure $1 \mathrm{G})$ and terminal stance phase $(P=.001$, Figure $1 \mathrm{G})$ in the MTP1 arthrodesis group, 

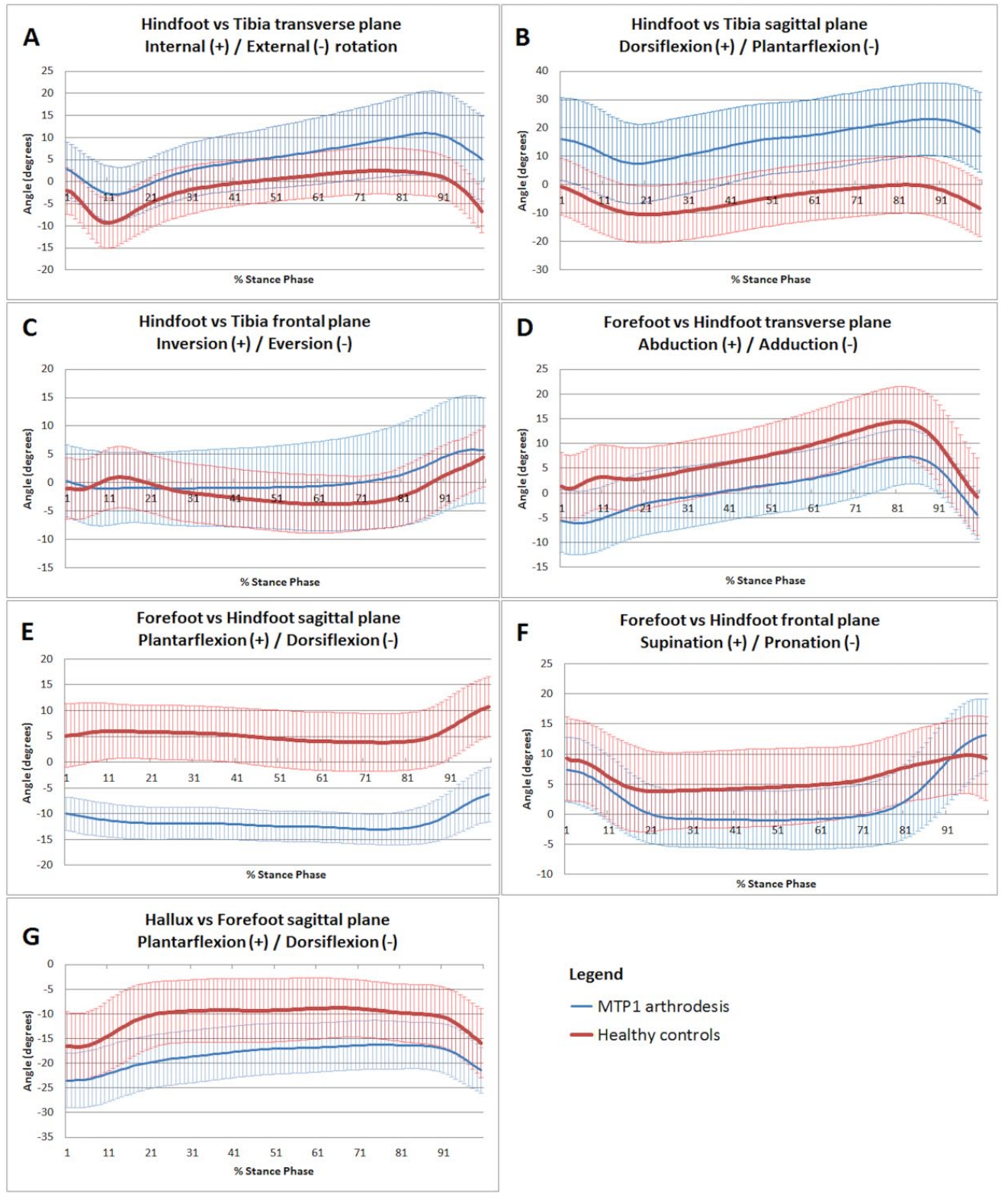

- MTP1 arthrodesis

Figure 2. Averaged absolute joint angles in the (A-C) hindfoot-tibia segment, (D-F) forefoot-hindfoot segment, and (G) halluxforefoot segment in the transverse, sagittal, and frontal planes during stance for the first metatarsophalangeal joint arthrodesis group and healthy controls.

which was the result of less plantarflexion of the hallux during loading response and less dorsiflexion of the hallux during terminal stance (Figure $2 \mathrm{G}$ ).

Evaluation of motion patterns of the segments of interest (Figure 3) and proximal joints (Supplement 2 in the online journal) showed no major differences between unilateral and bilateral treated patients. Differences in joint angles were below 5 degrees for all joints, except sagittal hip and knee joint motion, showing a maximum difference in joint angle of 7 degrees between those patients. Evaluation of healthy controls showed no significant differences in ROM and joint motion patterns between left and right feet (Supplement 3 in the online journal), which justified the usage of both left and right feet in this study. 

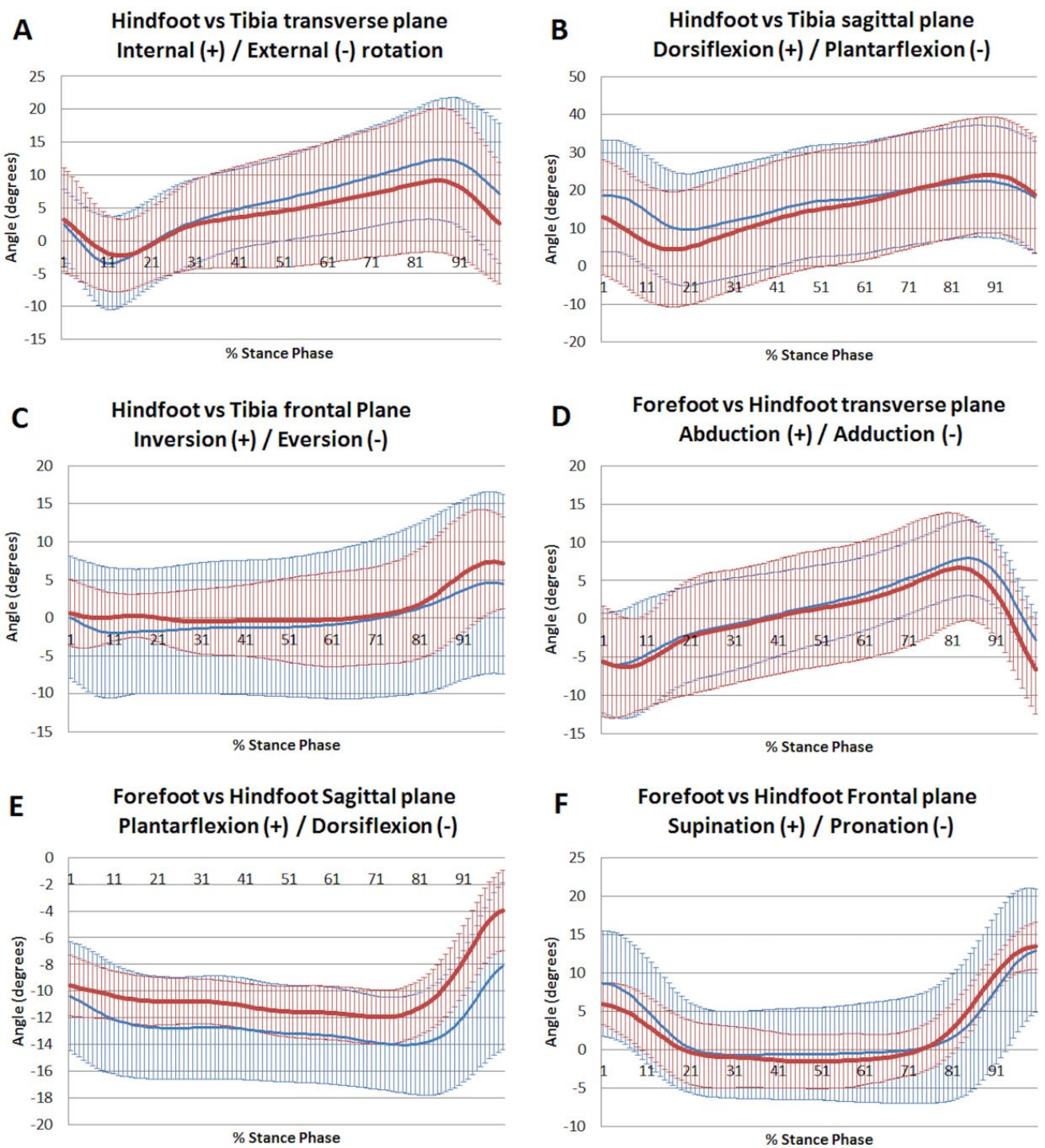

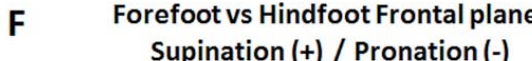

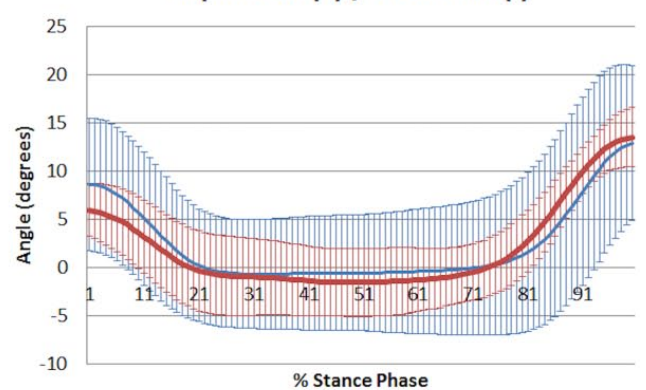

\section{G Hallux vs Forefoot Sagittal plane Plantarflexion (+) / Dorsiflexion (-)}

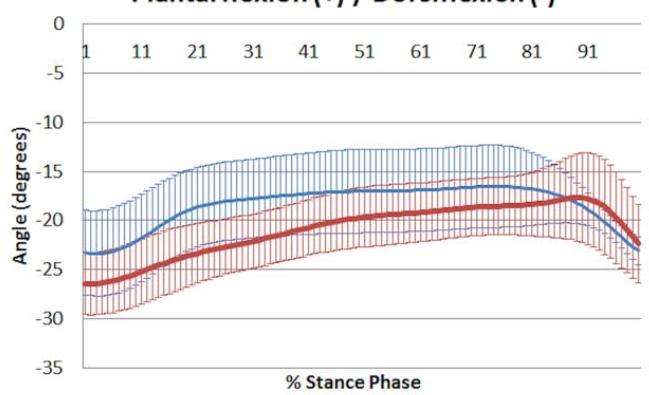

Figure 3. Average absolute joint angles in the (A-C) hindfoot-tibia segment, (D-F) forefoot-hindfoot segment, and (G) hallux-forefoot segment in the transverse, sagittal, and frontal planes during stance for patients with a unilateral and bilateral first metatarsophalangeal joint arthrodesis. 


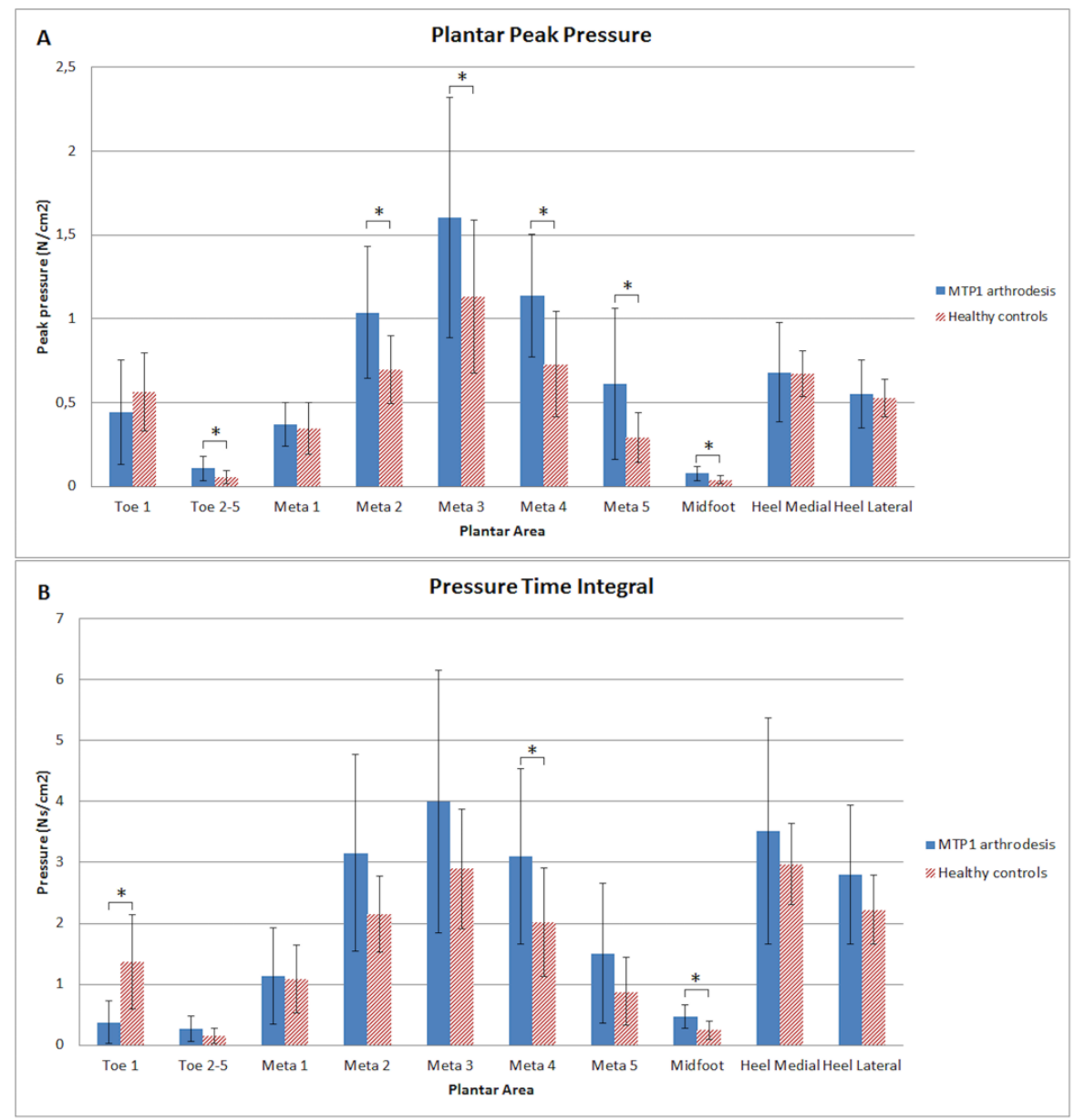

Figure 4. (A) Plantar peak pressure and (B) pressure time integrals for the 10 anatomical areas of the foot for the first metatarsophalangeal joint arthrodesis group and healthy controls. *Indicates a significant difference between both groups $(P<.05)$.

\section{Plantar pressure}

Significantly higher PPs were observed beneath the lesser toes (Toe $2-5, P=.013)$; second, third, fourth, and fifth metatarsal head areas $(P=.025, P=.038, P=.003$, and $P=.05$, respectively); and midfoot $(P=.017)$ in the MTP1 arthrodesis group, as is shown in Figure 4. Evaluation of the PTI showed a significantly lower PTI in the hallux area $\left(\mathrm{Toe}_{1}, P\right.$ $<.001)$, while a higher PTI was observed in the fourth metatarsal $(P=.03)$ and midfoot area $(P=.003)$ in the MTP1 arthrodesis group.

\section{Discussion}

In this study, biomechanical gait properties, plantar pressures, and radiographs were evaluated in patients who underwent an arthrodesis of the MTP1 joint for symptomatic OA of this joint. This was the first study investigating the compensatory mechanism of the foot after this intervention in order to restore the gait pattern. We hypothesized that the hindfoot and forefoot would compensate due to less eversion of the hindfoot, followed by increased supination of the forefoot. This compensatory mechanism subsequently results in decreased loading of the hallux and increased loading of the lesser metatarsals during stance.

As expected, our findings demonstrated an altered motion pattern in the forefoot and hindfoot after MTP1 arthrodesis. This motion pattern consisted of decreased eversion of the hindfoot during midstance, followed by increased internal rotation of the hindfoot in terminal stance, and ultimately increased supination and decreased adduction of the forefoot during preswing. In addition, decreased PTI beneath the hallux together with higher PTIs and PPs beneath the lesser metatarsals were observed. This consecutive altered motion pattern served as a compensatory mechanism in which the rigid hallux was avoided during roll-off. This was confirmed by the plantar pressure results showing a load transfer from the first ray toward the lesser 
metatarsals. These findings support our hypothesis that the hindfoot and forefoot are responsible for restoring the gait pattern after MTP1 arthrodesis.

To our knowledge, this was the first study evaluating foot and ankle kinematics after MTP1 arthrodesis with a multisegment foot model. The validated OFM was used to assess foot and ankle kinematics in our study., $9,15,37,39,41$ This foot model has been progressively used to gain more insight into the biomechanical consequences of foot and ankle pathologies on gait. ${ }^{18,38}$ The high reliability of the OFM for measuring joint kinematics during gait has been proved in several studies. The highest repeatability was reported in the sagittal plane, followed by the frontal and transverse planes. ${ }^{9,15,39,41}$ Previous studies evaluating gait properties after MTP1 arthrodesis are scarce and show a decrease in step length and step width. ${ }^{5,16,22}$ A decrease in step width was observed in this study, which is consistent with a previous study of Brodsky et al, ${ }^{5}$ who suggested that this resulted in increased stability during gait. However, we suggest that this is due to the higher number of women in the MTP1 arthrodesis group since it is known that step width is smaller in women. ${ }^{11,27}$ As described before, none of these previous studies were able to evaluate the effects of MTP1 arthrodesis on foot and ankle kinematics as the models used in these studies were not suitable for assessing foot and ankle kinematics. Therefore, the compensatory mechanism remained unclear.

From a kinematic point of view, the compensatory mechanism of the foot and ankle as shown in our study suggests decreased loading of the hallux with subsequently increased loading of the lateral plantar areas of the foot. As stated, the results support our hypothesis as a decreased PTI beneath the hallux together with higher PPs beneath the second, third, fourth, and fifth metatarsal heads and a higher PTI beneath the fourth metatarsal head were observed. This is contradictory to previous studies, which showed an increased PP beneath the hallux. Therefore, it was concluded that fusion of the MTP1 joint restored the weightbearing function of the first ray due to pain relief and mechanical stabilization of the medial column. ${ }^{12,13,16,25,30}$

A possible explanation for the differences in results between our study and previous pressure studies is the nature of measuring plantar pressures, which was performed dynamically in this study while assessed statically in most previously studies. ${ }^{12,13,25,30}$ In addition, previous studies were limited since they only reported PP, which gives information about the maximal pressure in an area during one timeframe but provides no information concerning the pressure load during the rest of the stance phase..$^{16,23,36}$ Our results perfectly demonstrate the additive value of assessing the PTI since this value showed that the hallux was less loaded during stance after MTP1 arthrodesis. If PP was used as our single pressure measurement outcome, this would have resulted in the incorrect conclusion that MTP1 arthrodesis restores the weight-bearing function of the hallux as no differences in PP beneath the hallux were observed between the groups.

Based on the observed compensatory mechanism, we expected to observe unloading of the first metatarsal head. This effect of MTP1 arthrodesis was not observed. It is known from the literature that the optimal DFA of the hallux ranges between 20 degrees and 25 degrees, with higher DFAs causing higher pressures beneath the first metatarsal. ${ }^{1,3}$ In our opinion, decreased PP or PTI beneath the first metatarsal head was not observed since patients included in this study had an average DFA of 30 degrees.

This was the first study investigating the compensatory mechanism of the foot with a multisegment foot model and assessing PTIs of plantar areas in patients with MTP1 arthrodesis. Despite the described findings, we acknowledge that this study had some limitations. Selection of a gender- and age-matched control group would have been more appropriate as significant differences in gender and age distribution were detected between the groups. Besides, a significant difference in height was detected between both groups. The number of studies evaluating the effect of age, height, and gender on gait parameters is limited. It is known that age and height mainly affects gait velocity and gait velocity subsequently strongly influences foot kinematics. ${ }^{2,8,11,20,27,28,33}$ Since gait velocity was comparable between both groups, the difference in age was deemed not to have influenced our results. In addition, the effect of gender on foot and ankle kinematics has not been defined yet, although some studies suggest a true gender effect in ankle motion in the sagittal plane. ${ }^{26,27,33}$ Therefore, the effect of gender cannot be completely ruled out. In addition, it is known that a bilateral intervention or disease can influence gait characteristics since the limbs do not act independently during gait. Kinematics of unilateral and bilateral treated patients were compared to assess this potential effect. Kinematics at the knee, hip, and pelvic levels were visually compared in order to elucidate whether compensation appeared at a distal level (ie, the foot) or at a more proximal level as well. Our data showed no major differences in segmental motion patterns, and maximum differences in joint angles were below 5 degrees for all motions (except sagittal hip and knee motion) at these proximal levels, resulting in the conclusion that compensation mainly occurred in the foot. Subsequently, foot kinematics of these patients were visually compared, showing small differences in joint angles (ranging between 2 degrees and 5 degrees) between those patients. Therefore, it was concluded that inclusion of bilaterally treated patients did not significantly influence our data. However, we were only able to assess this visually as the number of feet that were unilaterally and bilaterally treated was too small for statistical evaluation. Although both limbs do not act independently during gait, inclusion of both left and right feet of bilaterally evaluated healthy subjects was justified since no significant differences in ROM and joint 
motion patterns were observed between left and right feet. Furthermore, small errors in marker placement could result in variability despite the acceptable to good reproducibility of the OFM..$^{10,39,41}$ To minimize this effect, one experienced researcher placed all markers. In addition, as this was the first study evaluating foot and ankle kinematics after MTP1 arthrodesis, sample size was not calculated before the start of the study. This study was therefore limited due to the number of patients. As a result, inclusion of a patient with a more deviated gait pattern had a major influence on the results, as can be seen in the large variability in the joint motion patterns. Although variation in ROM and joint motion patterns existed between individuals, no major inconsistencies (ie, phase shifts) were detected between subjects.

\section{Conclusion}

This was the first study demonstrating that the hindfoot and forefoot compensate for the loss of motion after MTP1 arthrodesis, thereby resulting in a gait pattern in which the lesser metatarsals endured higher peak pressures while the hallux was less loaded during the stance phase of gait. These results indicate that the foot had the intrinsic capacity to compensate for the loss of motion of the hallux after MTP1 arthrodesis. We suggest that a preexisting reduced compensatory mechanism of the forefoot or hindfoot or the transfer of load from the first ray to the lesser metatarsals could result in persistence of symptoms in the minority of the patients who were dissatisfied after MTP1 arthrodesis. Prospective studies are necessary to demonstrate which of these explanations are the cause of the persistent complaints in the minority of the patients treated with an arthrodesis of the MTP1 joint.

\section{Authors' Note}

Since gait analysis studies were performed multidisciplinary in the Maastricht University Medical Centre, more than 6 authors were involved in this study. Jasper Stevens, MD, Mathijs C.H.W. Fuchs, MD, Lodewijk W. van Rhijn, Prof, MD, Joris P.S. Hermus, $\mathrm{MD}$, and Adhiambo M. Witlox, MD, PhD, were involved in collecting eligible participants, the surgical intervention, and evaluation of clinical functioning. Jasper Stevens, MD, Kenneth Meijer, $\mathrm{PhD}$, Wouter Bijnens, BScEng, Mathijs C.H.W. Fuchs, MD, Sander van Hoeve, MD, Martijn Poeze, MD, PhD, and Adhiambo $\mathrm{M}$. Witlox, $\mathrm{MD}, \mathrm{PhD}$, performed gait analysis and were involved in data collection. All authors were involved in analyzing kinematic data and plantar pressure data and participated in writing and revising the manuscript.

\section{Declaration of Conflicting Interests}

The author(s) declared no potential conflicts of interest with respect to the research, authorship, and/or publication of this article.

\section{Funding}

The author(s) received no financial support for the research, authorship, and/or publication of this article.

\section{Supplemental Material}

Supplementary material is available online with this article.

\section{References}

1. Alentorn-Geli E, Gil S, Bascuas I, et al. Correlation of dorsiflexion angle and plantar pressure following arthrodesis of the first metatarsophalangeal joint. Foot Ankle Int. 2013;34(4):504-511.

2. Arnold JB, Mackintosh S, Jones S, Thewlis D. Differences in foot kinematics between young and older adults during walking. Gait Posture. 2014;39(2):689-694.

3. Bayomy AF, Aubin PM, Sangeorzan BJ, Ledoux WR. Arthrodesis of the first metatarsophalangeal joint: a robotic cadaver study of the dorsiflexion angle. J Bone Joint Surg Am. 2010;92(8):1754-1764.

4. Bergin SM, Munteanu SE, Zammit GV, Nikolopoulos N, Menz HB. Impact of first metatarsophalangeal joint osteoarthritis on health-related quality of life. Arthritis Care Res (Hoboken). 2012;64(11):1691-1698.

5. Brodsky JW, Baum BS, Pollo FE, Mehta H. Prospective gait analysis in patients with first metatarsophalangeal joint arthrodesis for hallux rigidus. Foot Ankle Int. 2007;28(2):162165.

6. Calvo A, Viladot R, Gine J, Alvarez F. The importance of the length of the first metatarsal and the proximal phalanx of hallux in the etiopathogeny of the hallux rigidus. Foot Ankle Surg. 2009;15(2):69-74.

7. Camasta CA. Hallux limitus and hallux rigidus. Clinical examination, radiographic findings, and natural history. Clin Podiatr Med Surg. 1996;13(3):423-448.

8. Caravaggi P, Leardini A, Crompton R. Kinematic correlates of walking cadence in the foot. J Biomech. 2010;43(12):24252433.

9. Carson MC, Harrington ME, Thompson N, O'Connor JJ, Theologis TN. Kinematic analysis of a multi-segment foot model for research and clinical applications: a repeatability analysis. J Biomech. 2001;34(10):1299-1307.

10. Carty CP, Walsh HP, Gillett JG. Sensitivity of the Oxford Foot Model to marker misplacement: a systematic single-case investigation. Gait Posture. 2015;42(3):398-401.

11. Cho SH, Park JM, Kwon OY. Gender differences in three dimensional gait analysis data from 98 healthy Korean adults. Clin Biomech (Bristol, Avon). 2004;19(2):145-152.

12. Coughlin MJ. Rheumatoid forefoot reconstruction. A longterm follow-up study. J Bone Joint Surg Am. 2000;82(3):322341.

13. Coughlin MJ, Grebing BR, Jones CP. Arthrodesis of the first metatarsophalangeal joint for idiopathic hallux valgus: intermediate results. Foot Ankle Int. 2005;26(10):783-792.

14. Coughlin MJ, Shurnas PS. Hallux rigidus: demographics, etiology, and radiographic assessment. Foot Ankle Int. 2003;24(10):731-743. 
15. Curtis DJ, Bencke J, Stebbins JA, Stansfield B. Intra-rater repeatability of the Oxford Foot Model in healthy children in different stages of the foot roll over process during gait. Gait Posture. 2009;30(1):118-121.

16. Defrino PF, Brodsky JW, Pollo FE, Crenshaw SJ, Beischer AD. First metatarsophalangeal arthrodesis: a clinical, pedobarographic and gait analysis study. Foot Ankle Int. 2002;23(6):496-502.

17. Desandis B, Pino A, Levine DS, et al. Functional outcomes following first metatarsophalangeal arthrodesis. Foot Ankle Int. 2016;37(7):715-721.

18. Deschamps K, Birch I, Desloovere K, Matricali GA. The impact of hallux valgus on foot kinematics: a cross-sectional, comparative study. Gait Posture. 2010;32(1):102-106.

19. Doty J, Coughlin M, Hirose C, Kemp T. Hallux metatarsophalangeal joint arthrodesis with a hybrid locking plate and a plantar neutralization screw: a prospective study. Foot Ankle Int. 2013;34(11):1535-1540.

20. Dubbeldam R, Buurke JH, Simons C, et al. The effects of walking speed on forefoot, hindfoot and ankle joint motion. Clin Biomech (Bristol, Avon). 2010;25(8):796-801.

21. Fitzgerald JA. A review of long-term results of arthrodesis of the first metatarso-phalangeal joint. J Bone Joint Surg Br. 1969;51(3):488-493.

22. Galois L, Girard D, Martinet N, Delagoutte JP, Mainard D. [Optoelectronic gait analysis after metatarsophalangeal arthrodesis of the hallux: fifteen cases]. Rev Chir Orthop Reparatrice Appar Mot. 2006;92(1):52-59.

23. Gibson JN, Thomson CE. Arthrodesis or total replacement arthroplasty for hallux rigidus: a randomized controlled trial. Foot Ankle Int. 2005;26(9):680-690.

24. Goucher NR, Coughlin MJ. Hallux metatarsophalangeal joint arthrodesis using dome-shaped reamers and dorsal plate fixation: a prospective study. Foot Ankle Int. 2006;27(11): 869-876.

25. Henry AP, Waugh W, Wood H. The use of footprints in assessing the results of operations for hallux valgus. A comparison of Keller's operation and arthrodesis. J Bone Joint Surg Br. 1975;57(4):478-481.

26. Kerrigan DC, Todd MK, Della Croce U. Gender differences in joint biomechanics during walking: normative study in young adults. Am J Phys Med Rehabil. 1998;77(1):2-7.

27. Ko SU, Tolea MI, Hausdorff JM, Ferrucci L. Sex-specific differences in gait patterns of healthy older adults: results from the Baltimore Longitudinal Study of Aging. J Biomech. 2011;44(10):1974-1979.

28. Legault-Moore D, Chester VL, De Vries G. Multisegment foot kinematics during walking in younger and older adults. $J$ Clin Med Res. 2012;4(4):259-266.

29. Mann RA, Oates JC. Arthrodesis of the first metatarsophalangeal joint. Foot Ankle. 1980;1(3):159-166.

30. Mann RA, Thompson FM. Arthrodesis of the first metatarsophalangeal joint for hallux valgus in rheumatoid arthritis. $J$ Bone Joint Surg Am. 1984;66(5):687-692.

31. Melai T, IJzerman TH, Schaper NC, et al. Calculation of plantar pressure time integral, an alternative approach. Gait Posture. 2011;34(3):379-383.

32. Perry J. Gait Analysis: Normal and Pathological Function. Thorofare, NJ: Slack Incorporated; 1992.

33. Roislien J, Skare O, Gustavsen M, Broch NL, Rennie L, Opheim A. Simultaneous estimation of effects of gender, age and walking speed on kinematic gait data. Gait Posture. 2009;30(4):441-445.

34. Shurnas PS. Hallux rigidus: etiology, biomechanics, and nonoperative treatment. Foot Ankle Clin. 2009;14(1):1-8.

35. Smith RW, Reynolds JC, Stewart MJ. Hallux valgus assessment: report of research committee of American Orthopaedic Foot and Ankle Society. Foot Ankle. 1984;5(2):92-103.

36. Southgate JJ, Urry SR. Hallux rigidus: the long-term results of dorsal wedge osteotomy and arthrodesis in adults. J Foot Ankle Surg. 1997;36(2):136-140.

37. Stebbins J, Harrington M, Thompson N, Zavatsky A, Theologis T. Repeatability of a model for measuring multi-segment foot kinematics in children. Gait Posture. 2006;23(4):401-410.

38. Van Hoeve S, De Vos J, Verbruggen JP, Willems P, Meijer K, Poeze M. Gait Analysis and functional outcome after calcaneal fracture. J Bone Joint Surg Am. 2015;97(22):1879-1888.

39. Van Hoeve S, De Vos J, Weijers P, et al. Repeatability of the Oxford Foot Model for kinematic gait analysis of the foot and ankle. Clin Res Foot Ankle. 2015;3:711.

40. Van Saase JL, Van Romunde LK, Cats A, Vandenbroucke JP, Valkenburg HA. Epidemiology of osteoarthritis: Zoetermeer survey. Comparison of radiological osteoarthritis in a Dutch population with that in 10 other populations. Ann Rheum Dis. 1989;48(4):271-280.

41. Wright CJ, Arnold BL, Coffey TG, Pidcoe PE. Repeatability of the modified Oxford Foot Model during gait in healthy adults. Gait Posture. 2011;33(1):108-112. 